Gut, 1972, 13, 539-543

\title{
Site of the abnormal stimulus of gastric secretion after small bowel exclusion
}

\author{
B. BUXTON, A. E. O. WASUNNA, J. SAUNDERS, AND I. E. Gillespie \\ From the University Department of Surgery, Western Infirmary, Glasgow
}

SUMMARY In dogs with either vagally innervated or denervated pouches, the acid responses to a standard meal, a meal which bypassed the greater part of the small bowel, and a meal introduced directly into the small intestine were measured before and after exclusion of $75 \%$ of the small bowel.

After intestinal exclusion an increase in acid secretion was found in the latter part of the acid response to the standard meal and the intestinal meal. No increase in acid secretion resulted from the meals which bypassed the small bowel.

These findings suggest that an increase in stimulation from the remaining small intestine is responsible for the elevation in acid secretion following small bowel exclusion.

An increase in gastric secretion following extensive small bowel resection or exclusion in dogs has been reported on many occasions since it was first described by Sabsai (1963). Yet the site of the abnormality in the gastric secretory mechanism has not been precisely localized.

Theoretically, the increase in acid secretion could result from a change in vagal, antral, or intestinal stimulation of gastric secretion or from a change in the parietal cell response to these stimuli.

Sabsai (1963) showed that an increase in the sham feeding response occurred after small bowel resection in dogs with vagally innervated pouches or gastric fistulae. Landor (1969), using dogs with Heidenhain pouches, demonstrated that an increase in gastric secretion could occur in the absence of the gastric antrum, indicating that the change in stimulation was arising, at least in part, from the small intestine.

The purpose of this study was to determine the relative contributions of the vagus, the antrum, and the small intestine to the increase in acid secretion after small bowel exclusion. This was approached by measuring the acid responses alternately from stimulation of the stomach and the small intestine, with in each case the predominant exclusion of the other, before and after small bowel exclusion in dogs, some with vagally innervated pouches and some with vagally denervated pouches.

All correspondence to be addressed to: Professor Iain E. Gillespie, Department of Surgery, The Royal Infirmary, Manchester, M13 9WL.

Received for publication 8 May 1972.

\section{Materials and Methods}

Three adult mongrel dogs weighing $16-19 \mathrm{~kg}$ were prepared each with a vagally innervated fundic pouch (Gregory, Hallenbeck, and Code, 1942). The presence of vagal innervation to the pouches was confirmed by testing with intravenous insulin 0.4 $\mathrm{u} / \mathrm{kg}$, applying Hollander's criteria of incomplete denervation (Hollander, 1948). In addition, a permanent jejunal fistula was created $15 \mathrm{~cm}$ beyond the duodeno-jejunal flexure by means of a wide-bore titanium cannula of the Gregory pattern. A further four adult mongrel dogs, weighing $15-20 \mathrm{~kg}$, were prepared with a vagally denervated pouch and a jejunal fistula with a valve to prevent reflux of food introduced through the fistula (Figure 1). After operation, the dogs were left for a recovery period of 28 days. Each test was preceded by an 18-hour fast. In each experiment, after a 30-minute basal acid collection, the acid output was recorded at half hourly intervals for six hours following either a standard, a diverted, or an intestinal meal.

\section{A STANDARD MEAL}

This consisted of $400 \mathrm{~g}$ of a commercial dog food (Banquet) composed of $11.5 \%$ protein, $7.5 \%$ fat, $1.5 \%$ carbohydrate, $78.3 \%$ water, and $1.2 \%$ mineral ash.

A DIVERTED MEAL

The same $400 \mathrm{~g}$ meal was used, but the partly digested food was diverted to the exterior through the fistula. 

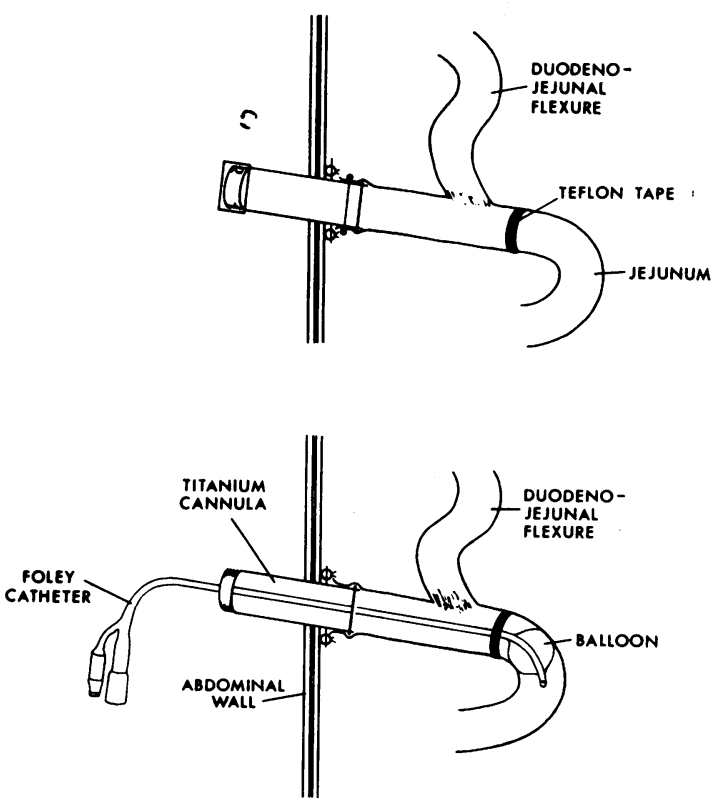

Fig. 1 Jejunal fistula with a valve.

In this way, food bypassed the greater part of the jejunum and ileum. Thus, the acid response was predominantly from the vagus and antrum in dogs with vagally innervated pouches and predominantly from the antrum in dogs with vagally denervated pouches. The effluent from each fistula was collected and stored at $-15^{\circ} \mathrm{C}$.

AN INTESTINAL MEAL

The same partly digested meal was placed directly into the jejunum. Prior to replacement, the food was warmed to $38^{\circ} \mathrm{C}$ in a water bath and then returned to the jejunum from a reservoir situated $15 \mathrm{~cm}$ above the fistula, at exactly the same rate as it had been collected.

The acid content of each sample was measured by titration of a $1 \mathrm{ml}$ aliquot with $0.01 \mathrm{~N}$ sodium hydroxide to an endpoint of $p \mathrm{H} 6 \cdot 8-8 \cdot 4$, using phenol red as the indicator. The acid response from each of the test meals was recorded on a minimum of three occasions in each dog.

At a second operation, the central $75 \%$ of the small intestine was excluded in the form of a ThiryVella loop. Continuity was restored by a single layer end-to-end anastomosis. After a further recovery period of 28 days, the acid responses to the standard, the diverted, and the intestinal meals were retested.

The acid response of the innervated pouches to graded doses of pentagastrin $2-8 \mu \mathrm{g} / \mathrm{kg}$-hr given by a constant intravenous infusion was tested before and after intestinal exclusion.

An $x$-ray study was performed in each dog. Hourly $x$-ray films were taken after $50 \mathrm{~g}$ of barium sulphate mixed with the standard meal was fed to the dogs with the fistula open until the stomach was empty. Reflux was studied by taking further films after injecting a mixture of barium sulphate and $0.9 \%$ sodium chloride into the cannula at the same rate as that used for the intestinal meal. The $x$-ray studies confirmed the effectiveness of the fistulae in diverting the meal to the exterior and verified the absence of reflux into the antrum of barium introduced into the jejunum.

\section{Results}

\section{STANDARD MEAL}

Innervated pouches (Figure 2)

After intestinal exclusion, a significant increase in acid secretion was present in the fifth and sixth hours after the meal. The total acid response for the sixhour period was increased by $27 \%(\mathrm{P}<0.05)$.

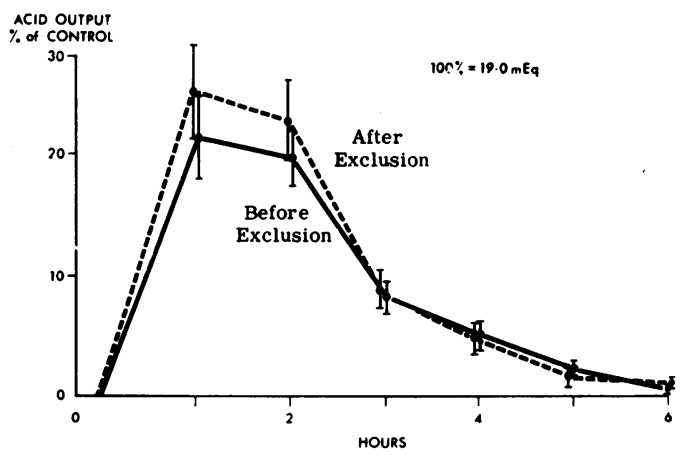

Fig. 2 The effect of $75 \%$ intestinal exclusion on the mean hourly acid response to a standard meal in dogs with vagally innervated pouches. In this and subsequent figures, the solid line represents the mean acid response before exclusion, and the interrupted line the mean acid response after exclusion.

The vertical bar represents the standard errors of mean.

The hourly acid output from each dog has been expressed as a percentage of the mean six-hour total acid response before exclusion (control) for that dog, so that the acid outputs from different dogs were comparable.

Denervated pouches (Figure 3)

After intestinal exclusion, the acid response in the second hour was less than the response before exclusion. However, by the fourth hour, the acid output was significantly greater. In the fifth and sixth 


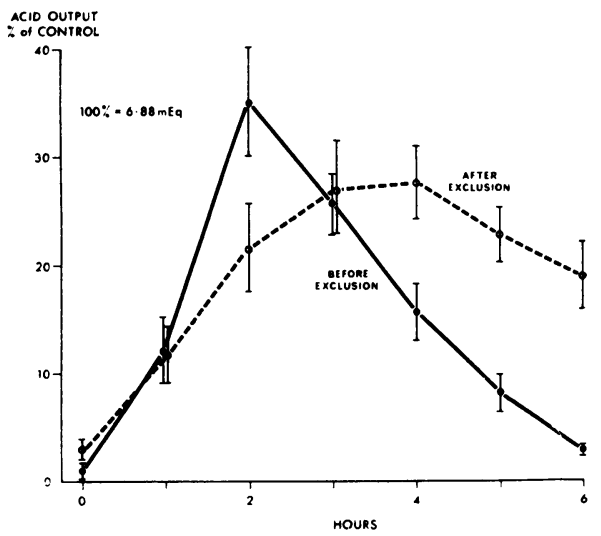

Fig. 3 The effect of $75 \%$ intestinal exclusion on the mean hourly acid response to a standard meal in dogs with vagally denervated pouches.

hours, this difference was significant at the $1 \%$ level. The mean total acid response for the six-hour period was not significantly increased.

\section{DIVERTED MEAL}

Innervated pouches (Figure 4)

After exclusion of $75 \%$ of the small intestine, the mean hourly acid output in response to this meal remained unchanged throughout the six hours. The total acid response from this meal was not significantly altered.

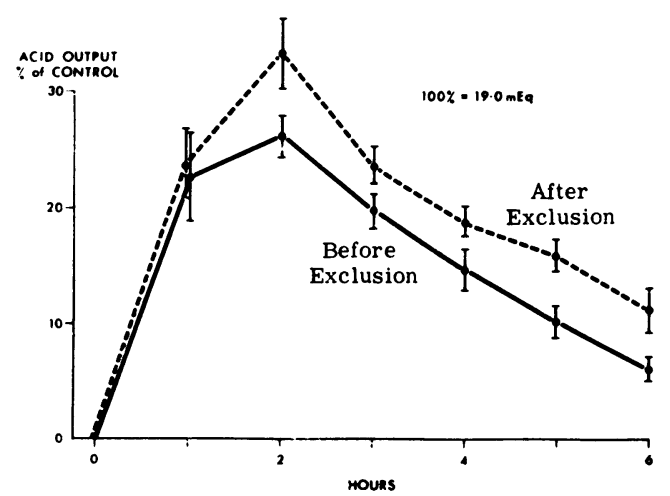

Fig. 4 The effect of $75 \%$ intestinal exclusion on the mean hourly acid response to a diverted meal in dogs with vagally innervated pouches.

Denervated pouches (Figure 5)

After exclusion of $75 \%$ of the small intestine, the acid response was significantly less in the second hour of the second hour of the meal compared with before exclusion. Throughout the remainder of the meal response to the acid outputs were similar. The total acid output resulting from this meal was unaltered.

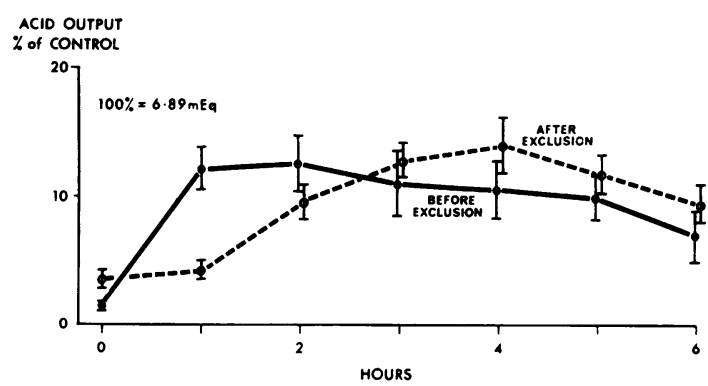

Fig. 5 The effect of $75 \%$ intestinal exclusion on the mean hourly acid response to a diverted meal in dogs with vagally denervated pouches.

\section{INTESTINAL MEAL}

Innervated pouches (Figure 6)

After intestinal exclusion, a significant increase in acid secretion at the $1 \%$ level was present in the fourth hour after commencement of the intestinal meal. The total acid response to this meal was increased by $27 \%(\mathrm{P}<0.05)$.

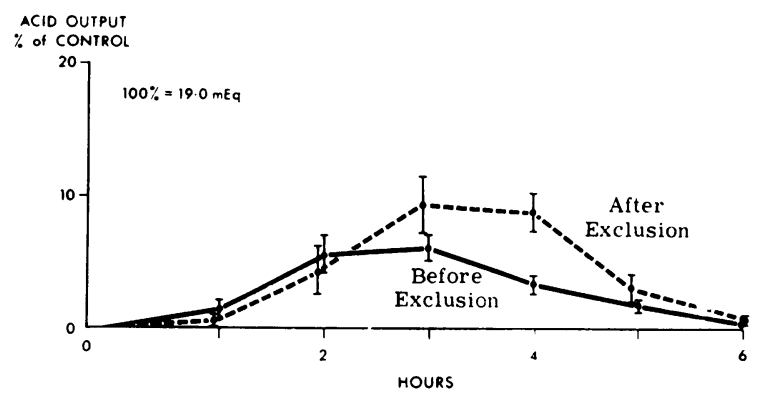

Fig. 6 The effect of $75 \%$ intestinal exclusion on the mean hourly acid response to an intestinal meal in dogs with vagally innervated pouches.

\section{Denervated pouches (Figure 7)}

After intestinal exclusion, the acid output was significantly less in the second hour after commencement of the intestinal meal. In the sixth hour the acid output was significantly greater. The difference in the total six-hour acid response was not statistically significant. 


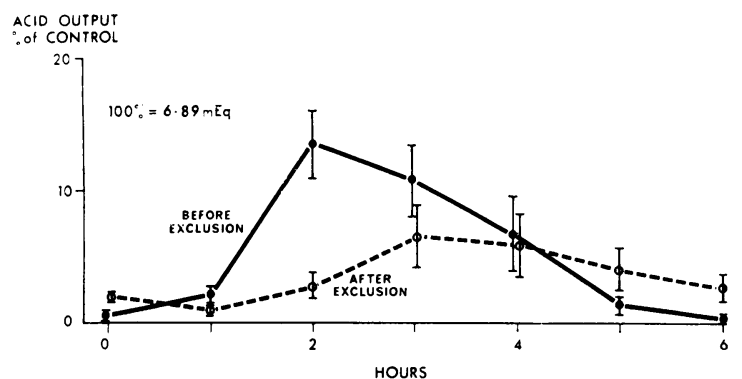

Fig. 7 The effect of $75 \%$ intestinal exclusion on the mean hourly acid response to an intestinal meal in dogs with vagally denervated pouches.

ACID RESPONSE TO PENTAGASTRIN (FIGURE 8) The acid response to pentagastrin $1-4 \mu \mathrm{g} / \mathrm{kg}-\mathrm{hr}$ was not significantly altered by intestinal exclusion, but that to pentagastrin $8 \mu \mathrm{g} / \mathrm{kg}$-hr was significantly less after exclusion.

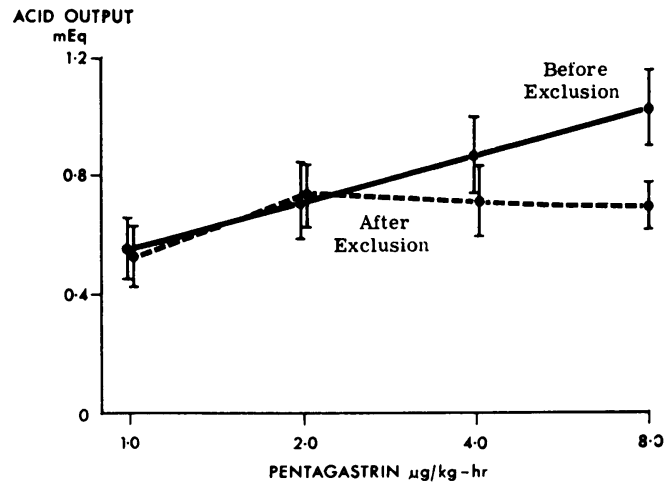

Fig. 8 The effect of $75 \%$ intestinal exclusion on the acid response to intravenous pentagastrin in dogs with vagally innervated pouches.

\section{Discussion}

These experiments showed an increase in the latter part of the acid response to a meal after exclusion of $75 \%$ of the small bowel. The latter part of the acid response to a meal is generally attributed to stimuli arising from the intestine. An increase in the latter part of the meal response after small bowel exclusion therefore suggests that there is a greater contribution from the remaining small intestine. In contrast, no change in acid response resulted from the diverted meal which bypassed the greater part of the small bowel. Under these circumstances it would be expected that the acid response was predominantly from the vagus and antrum. The response to pentagastrin did not increase after small bowel exclusion, indicating that there was no gross increase in sensitivity of the parietal cell area.

The exact contribution of the duodenum to the increase in gastric secretion is uncertain. A small increase in stimulation from the duodenum after small bowel exclusion might be obscured by the dominant effect of the vagus and antrum in the acid response to the diverted meal. It is of interest to note that the latter part of the diverted meal response in dogs with vagally denervated pouches tended to be higher after intestinal exclusion suggesting that the duodenum might be providing increased stimulation. It would have been of interest to clarify the role of the duodenum by placing the fistula immediately distal to the pylorus thus including the duodenum with the jejunum and ileum. However, this would have led to a high risk of reflux into the gastric antrum when food was introduced through the fistula.

The finding that the intestine itself is at least partly responsible for the increase in acid secretion after small bowel exclusion is consistent with previous experimental data. Studies in dogs with Heidenhain pouches have shown that an increase in gastric secretion can occur in the absence of vagal innervation of the gastric fundic mucosa (Sabsai, 1963; Landor and Baker, 1964; Frederick, Sizer, and Osborne, 1965; Westerheide, Elliot, and Hardacre, 1965; Reul and Ellison, 1966; Osborne, Frederick, Sizer, Blair, Cole, and Thum, 1966; Kerr, Elliott, and Endahl, 1968; Copeland, Miller, and Smith, 1968; Windsor, 1968; Landor, 1969; Santillana, Wise, Schuck, and Ballinger, 1969; Windsor, Fejfar, and Woodward, 1969; Burrington and Hamilton, 1969; Yakimets and Bondar; (1969); Landor, Behringer, and Wild, 1970; Landor, Wild, and Behringer, 1970). Landor (1969) found that an increase in acid secretion followed small bowel resection in the absence of the gastricantrumin dogs with Heidenhain pouches. Kerr et al (1968) had made the same observation previously. They had excluded or resected the small intestine either before or after antrectomy. An increase in acid secretion followed the intestinal procedure irrespective of whether the antrectomy had been performed first.

If the portion of small intestine remaining after exclusion of a sizeable segment is directly responsible for the increase in gastric acid response to a meal, this could be explained by either a true increase in stimulation, or a decrease in inhibition of gastric secretion, or possibly a combination of both mechanisms.

Parallel observations with meals containing differ- 
ent quantities of fat (Buxton et al) suggest that the amount of inhibition of gastric acid secretion caused by this substance may indeed be reduced, but that this alone is insufficient to account for the total increase in gastric acid response to a meal, and therefore a true increase in stimulation from the residual small intestine is probably a more important factor.

\section{References}

Burrington, J. D., and Hamilton, J. R. (1969). Steatorrhea after massive bowel resection: effects of surgical reduction of gastric acid secretion. Surg. Forum, 20, 341-345.

Copeland, E. M., Miller, L. D., and Smith, G. P. (1968). The complex nature of small bowel control of gastric secretion. Ann. Surg., $168,36-46$.

Frederick, P. L., Sizer, J. S., and Osborne, M. P. (1965). Relation of massive bowel resection to gastric secretion. New Engl.J. Med., 272, 509-514.

Gregory, R. A., Hallenbeck, G. A., and Code, C. F. (1942). A modification of the method of Hollander and Jemerin for making Pavlov pouches. Proc. Soc. exp. Biol. (N.Y.), 49, 400-403.

Hollander, F. (1948). Laboratory procedures in the study of vagotomy (with particular reference to the insulin test). Gastroenterology, $11,419-425$.

Kerr, G., Elliot, D. W., and Endahl, G. L. (1968). Effect of antrectomy on gastric acid hypersecretion induced by isolation of the proximal small bowel. Amer. J. Surg., 115, 157-164.

Landor, J. H. (1969). Intestinal resection and gastric secretion in dogs with antrectomy. Arch. Surg., 98, 645-646.
Landor, J. H., and Baker, W. K. (1964). Gastric hypersecretion produced by massive small bowel resection in dogs.J. Surg. Res., $4,518-522$.

Landor, J. H., Behringer, B. R., and Wild, R. A. (1970). The effect of enterectomy on gastric secretion in dogs with biliary fistulas. Amer. J. dig. Dis., 15, 633-636.

Landor, J. H., Wild, R. A., and Behringer, B. R. (1970). The influence of dietary fat on the gastric secretory response to pancreatic duct ligation or small bowel resection. Surgery, 68, 831-836.

Osborne, M. P., Frederick, P. L., Sizer, J. S., Blair, D., Cole, P., and Thum, W. (1966). Mechanism of gastric hypersecretion following massive intestinal resection: clinical and experimental observations. Ann. Surg., 164, 622-634.

Reul, G. J., and Ellison, E. H. (1966). Effect of seventy-five per cent distal small bowel resection on gastric secretion. Amer.J. Surg., 111, $772-776$.

Sabsai, B. I. (1963). The effect of extensive resection of the p-oximal and distal portions of the small intestine on canine gastric secretion. Bull. exp. Biol. Med., 55, 387-390.

Santillana, M., Wise, L., Schuck, M., and Ballinger, W. F., II (1969). Changes in gastric acid secretion following resection or exclusion of different segments of the small intestine. Surgery, $65,777-782$.

Westerheide, R. L., Elliott, D. W., and Hardacre, J. M. (1965). The potential of the upper small bowel in regulating acid secretion. Surgery, 58, 73-83.

Windsor, C. W. O. (1968). Gastric secretion following massive small intestinal resection. Brit. J. Surg., 55, 392.

Windsor, C. W. O., Fejfar, J., and Woodward, D. A. K. (1969). Gastric secretion after massive small bowel resection. Gut, 10, 779-786.

Yakimets, W. W., and Bondar, G. F. (1969). Hormonal stimulatory mechanism producing gastric hypersecretion following massive small intestinal resection. Canad.J. Surg., 12, 241-244. 